\title{
ANAESTHETIC CONSIDERATIONS IN PATIENTS WITH MUSCULAR DYSTROPHY UNDERGOING SPINAL FUSION AND HARRINGTON ROD INSERTION
}

\author{
Brian Milne and José K. Rosales
}

\begin{abstract}
Charts of nine patients with Duchenne and one with Becker's muscular dystrophy who had undergone spinal fusion and Harrington rod insertion for scoliosis were reviewed retrospectively. The mean age was 15 years and mean angle of scoliosis was 69 degrees. Preoperative pulmonary function studies showed a restrictive defect with a mean vital capacity of $1.3 \pm 0.69$ litres, $35 \pm 20$ per cent of predicted value, $33 \pm 20 \mathrm{ml} \cdot \mathrm{kg}^{-1}$ and a mean inspiratory capacity of $0.99 \pm 0.5$ litres, $23 \pm 13 \mathrm{ml} \cdot \mathrm{kg}^{-1}$. There were no anaesthetic complications during operation and obstructive cardiomyopathy, hyperpyrexia, hyperkalaemia and rhabdomyolysis were not problems. Succinylcholine was avoided. One patient developed an arrhythmia postoperatively and one patient whose postoperative problems included tracheostomy, pneumonia and sepsis could not be weaned from the ventilator and died 11 weeks after operation. As assessing risk and survival of the operation depends on objective pulmonary function, a vital capacity of at least $20 \mathrm{ml} \cdot \mathrm{kg}^{-1}$ in the range of 30 per cent of predicted volume with an inspiratory capacity of at least $15 \mathrm{ml} \cdot \mathrm{kg}^{-1}$ would appear to be adequate in patients with muscular dystrophy requiring Harrington rod insertion. Other factors including the rapidity of progression of the muscular disease, other respiratory and cardiovascular problems, and disease such as obesity should also be considered.
\end{abstract}

KEY WORDS: SURGERY, spinal fusion, Harrington rod; CoMPLICATIONS, muscular dystrophy, scoliosis, pulmonary function.

SCOLIOSIS OCCURS with high frequency in patients with Duchenne muscular dystrophy and patients may require general anaesthesia for spinal fusion and Harrington rod insertion. Indications for surgery include the degree and progression of the spinal deformity and the progression of the dystrophic disease. A lumbar curve of 35 degrees with rotation of 15 degrees at the apex presages progressive deformity and at this point prophylactic long spinal fusion can be offered. ${ }^{1.2}$

The childhood or Duchenne form of muscular dystrophy (incidence $0.14 / 1,000$ children) is $\mathrm{X}$-linked (genes responsible for $\mathrm{X}$-linked disorders are located on the $\mathrm{X}$ chromosome) and classically occurs only in males. The diagnosis is usually made in early childhood with patients

Brian Milne, M.D., M.Sc., F.R.C.P. (C), Fellow, Department of Anaesthesia, Montreal Children's Hospital, McGill University, presently Assistant Professor, Department of Anaesthesia and Pharmacology, Queen's University, Kingston, Ontario; José K. Rosales, M.D., F.R.C.P. (C), Anaesthetist-in-Chief, Montreal Children's Hospital, Associate Professor, McGill University, Montreal Canada.

Address Correspondence to: Dr. J.K. Rosales, Anaesthetist-in-Chief, Montreal Children's Hospital, 2300 Tupper Street, Montreal, Quebec H3H IP3. presenting with slow motor development, waddling gait, difficulty in climbing stairs and hypertrophy of calf muscles. The term "pseudohypertrophy" is used and although initially hypertrophied muscles have considerable strength, they are later weak due to fatty infiltration. Ambulation is usually impossible by age 12 and death occurs before age 20 in 75 per cent of patients due to restrictive respiratory failure, heart involvement or aspiration pneumonitis. ${ }^{3}$ Becker's muscular dystrophy is similar to the Duchenne type but less severe.

Anaesthetic considerations in patients with Duchenne muscular dystrophy include respiratory weakness with resultant alveolar hypoventilation, microatelectasis and restrictive respiratory failure, decreased ability to cough and the possibility of aspiration, obstructive cardiomyopathy, tachycardias, hyperpyrexia usually not developing into malignant hyperthermia, hyperkalaemia and rhabdomyolysis. ${ }^{4,5}$ Coupled with these are the problems relating to scoliosis: ventilation-perfusion inhomogeneity, malformation or an acquired defect of the respiratory centers in conjunction with increased work of breathing, and pulmonary hypertension and cor pulmonale. 6

Can. Anaesth. Soc. J., vol. 29, no. 3, May 1982 
TABLE I

Preoperative Pulmonary Function Results

\begin{tabular}{|c|c|c|c|c|c|c|}
\hline $\mathrm{n}=6$ & Mean $\pm S D$ & $\begin{array}{l}\% \text { Predicted } \\
\text { Mean } \pm S D\end{array}$ & $\begin{array}{c}\mathrm{ml} \cdot \mathrm{kg}^{-1} \\
\text { Mean } \pm \mathrm{SD}\end{array}$ & $\mathbf{n}=\mathbf{9}$ & Mean $\pm \mathrm{SD}$ & $\begin{array}{l}\% \text { Predicted } \\
\text { Mean } \pm \text { SD }\end{array}$ \\
\hline $\begin{array}{l}\text { VC (L) } \\
\text { IC (L) } \\
\text { FRC (L) } \\
\text { RV (L) } \\
\text { TLC (L) } \\
\text { RV/TLC\% }\end{array}$ & $\begin{array}{l}1.39 \pm 0.68 \\
0.99 \pm 0.50 \\
1.66 \pm 0.45 \\
1.26 \pm 0.29 \\
2.65 \pm 0.62 \\
50 \pm 16\end{array}$ & $\begin{array}{r}35 \pm 20 \\
- \\
66 \pm 19 \\
120 \pm 25 \\
51 \pm 16 \\
-\end{array}$ & $\begin{array}{c}33 \pm 20 \\
23 \pm 20 \\
- \\
- \\
-\end{array}$ & $\begin{array}{l}\text { FVC (L) } \\
\mathrm{FEV}_{1}(\mathrm{~L}) \\
\mathrm{FEV}_{1} / \mathrm{FVC} \% \\
\mathrm{FEF}(25-71) \mathrm{L} / \mathrm{sec} \\
\mathrm{PEF}(\mathrm{L} / \mathrm{sec})\end{array}$ & $\begin{array}{c}1.5 \pm 0.8 \\
1.3 \pm 0.7 \\
82 \pm 5 \\
1.94 \pm 0.95 \\
2.57 \pm 1.16\end{array}$ & $\begin{array}{c}40 \pm 21 \\
37 \pm 21 \\
- \\
51 \pm 24 \\
34.8 \pm 14.7\end{array}$ \\
\hline
\end{tabular}

VC - vital capacity.

IC - inspiratory capacity.

FRC - functional residual capacity.

RV - residual volume.

TLC - total lung capacity.

FVC - forced vital capacity.

FEV, - forced expiratory volume (first second).

FEF - forced expiratory flow rate (middle half of the total expiration).

PEF - peak expiratory flow rate.

We present a review of 10 patients with muscular dystrophy who had spinal fusion and Harrington rod insertion at Montreal Children's Hospital, and a discussion of the anaesthetic problems.

\section{Subjects aNd Methods}

Charts of nine patients with Duchenne muscular dystrophy and one with Becker's muscular dystrophy who had undergone spinal fusion and Harrington rod insertion were reviewed retrospectively. Operations were done during the period July 1979 to February 1981. All patients were male with age ranging from 10-23, with a mean of 15 years. The mean weight was $47 \pm$ $14 \mathrm{~kg}$.

\section{RESULTS}

The mean Cobb angle ( \pm SD) of scoliosis determined by radiological measurement was 69 \pm 22 degrees. (The Cobb angle is the angle of transection between a line drawn perpendicular to the upper margin of the vertebra which inclines most toward the concavity and a line drawn on the inferior border of the lower vertebra with the greatest angulation towards the concavity.)

Preoperative pulmonary function flow rates were determined in nine patients and static lung volumes were studied in six (Table I). Results of pulmonary function studies were compatible with a restrictive defect. Lung volumes were low with vital capacity (VC) being greatly reduced (mean 35 per cent of predicted values range 12-68 per cent) with preservation of residual volume. Dynamic studies showed a decrease in forced vital capacity (FVC) and forced expiratory volume first second $\left(\mathrm{FEV}_{1}\right)$ which was consistent with a reduction in $\mathrm{VC}$.

Only one patient showed evidence of cor pulmonale, with evidence of right ventricular hypertrophy on ECG and echocardiography.

General anaesthesia was induced with thiopentone in nine patients and with fentanyl, droperidol and diazepam in one. An electrocardiograph, nasopharyngeal temperature probe and oesophageal stethoscope were used to monitor cardiac activity, temperature, heart sounds and ventilation. Two wide bore intravenous cannulae were inserted for fluid administration and a radial artery was cannulated for continuous blood pressure monitoring. Patients were placed prone on the operating table over a Relton frame, with pressure on the abdomen avoided.

Anaesthesia was maintained with nitrous oxide and fentanyl in four cases, with nitrous oxide, fentanyl and halothane in four and with halothane and nitrous oxide in two, with controlled ventilation. Either pancuronium or tubocurarine was used for muscle relaxation. Succinylcholine was avoided in all cases. One patient had had previous dental surgery under general anaesthesia with thiopentone, succinylcholine and halothane with no sequelae. Hypotension induced with sodium nitroprusside was used in five patients.

Intraoperative arterial blood gases demonstrated no hypoxaemia or carbon dioxide reten- 
tion. No tachyarrhythmias were noted during operation, although one patient had persistent bigeminy in the recovery room, which was treated with lidocaine. This patient had also had an episode of supraventicular tachycardia after a hamstring release, and one other patient had supraventricular tachycardia after a previous anaesthetic.

Blood replacement averaged $3,140 \mathrm{ml}$ or 96 per cent of the estimated blood volume.

There were no episodes of hyperpyrexia or rhabdomyolysis. (Rhabdomyolysis is destruction of skeletal muscle as evidenced by myoglobinaemia and myoglobinuria.) All patients were given neostigmine and atropine to reverse muscle paralysis at the end of the procedure. In all patients but one the trachea was extubated at the end of the operation and no ventilatory assistance was required as assessed by arterial blood gases and clinical evaluation. This one patient required prolonged ventilation due to carbon dioxide retention and post-operative problems included the need for tracheostomy, bilateral lower lobe pneumonia, right pleural effusion, urinary tract infection, and sepsis. Attempts at weaning with intermittent mandatory ventilation failed, and he died 11 weeks after operation. This patient was known to be at high risk before operation because of his progressive disease, obesity, a VC of 0.55 litre (12 per cent of predicted, $8.5 \mathrm{ml} \cdot \mathrm{kg}^{-1}$ ), and IC of 0.36 litre $\left(5.5 \mathrm{ml} \cdot \mathrm{kg}^{-1}\right)$. However, it was felt that the risk was warranted as the operation might have enabled him to sit up and would facilitate his care, as he had been confined to bed.

\section{Discussion}

The specific considerations relating to Duchenne muscular dystrophy and anaesthesia concern obstructive cardiomyopathy, hyperpyrexia, hyperkalaemia and rhabdomyolysis. These were not a problem in this series. The avoidance of succinylcholine no doubt prevented the occurrence of rhabdomyolysis and hyperkalaemia. Only one patient developed an arrhythmia after Harrington rod insertion, although two patients had had previous episodes of supraventricular tachycardia after general anaesthesia for other surgical procedures.

The major problem in patients with muscular dystrophy and scoliosis undergoing spinal fusion and Harrington rod instrumentation is the combined effect on respiratory function of a disease which causes progressive weakness of respira- tory muscles and of a disorder of the thoracic cage. Respiratory weakness due to Duchenne muscular dystrophy leads to restrictive respiratory failure, which may not be recognized due to inactivity before operation, and to a decreased ability to cough, which may lead to retention of secretions, atelectasis and pneumonia.

While patients with idiopathic scoliosis with a deformity of less than $70^{\circ}$ usually have an asymptomatic cardiorespiratory status, ${ }^{6}$ the changes in lung function caused by more severe scoliosis include reduction in lung volume, increase in the work of breathing, and abnormal ventilation-perfusion ratios with hypoxaemia, followed later by carbon dioxide retention, pulmonary hypertension, cor pulmonale and respiratory acidosis. ${ }^{7}$

We are thus faced with the problem of assessing risk in these patients and ensuring that they are in optimum condition before operation. A history of rapid progression of the muscular disease, pulmonary complications such as recurring pneumonia, and shortness of breath which may be difficult to quantify due to the patient's low level of activity, would increase risk. Physical examination should focus on the abnormalities of the respiratory and cardiovascular systems, assessing chest expansion, use of accessory muscles, and evidence of cor pulmonale. Auscultation during forced expiration and cough may be helpful. ${ }^{8}$

A chest $x$-ray and arterial blood gas analysis should be done preoperatively. Evidence of hypoxaemia and carbon dioxide retention indicate increased risk and suggest the need for post-operative ventilation, as patients with restrictive disease do not retain carbon dioxide until they are on the brink of decompensation. ${ }^{8}$

The minimum requirements of objective pulmonary function to warrant operation in these patients are difficult to define, especially considering that there is progressive muscular disease, life expectancy is limited, and the physiological benefit of spinal fusion may be much less obvious than the anatomical improvement of the spinal curvature. ${ }^{9}$ However, the fusion may afford the patient a better quality of life by enabling him to sit up in a wheelchair, bringing the pelvis into a more horizontal plane for more comfortable sitting, and lengthening the trunk to allow greater diaphragmatic excursion.

The VC appears to be the most important single measurement that can be obtained ${ }^{\prime}$ and a FVC of less than $20 \mathrm{ml} / \mathrm{kg}^{10}$ indicates increased risk and the need for post-operative ventilation. 
Froese has outlined the importance of the IC, which she terms "usable VC", when trying to predict the ability to breath post-operatively. She states that even with perfectly normal lungs it is rare for a person to sustain ventilation for prolonged periods and to clear secretions with an IC of less than $15 \mathrm{ml} / \mathrm{kg}^{8} \mathrm{~A}$ VC of less than 50 per cent of predicted volume may also be expected to increase risk. ${ }^{11}$

Robin has reported on a series of seven patients with Duchenne muscular dystrophy requiring spinal fusion and Harrington rod instrumentation and stated that there were no respiratory complications of significance, although he did not report on pulmonary function. ${ }^{12}$ In another series patients were admitted to hospital for evaluation if the $\mathrm{VC}$ was greater than 30 per cent of predicted volume and in 10 patients operated on (mean VC 47 per cent) the duration of tracheal intubation varied from $0-17$ days, with most from 0-3 days. Post-operatively one patient had three episodes of cardiopulmonary arrest from which he was resuscitated, and another developed pneumonia. ${ }^{1}$ The patient who died in our series required prolonged mechanical ventilation and could not be weaned with intermittent mandatory ventilation. This patient had a VC of 0.55 litre ( 12 per cent predicted, $\left.8.5 \mathrm{ml} \cdot \mathrm{kg}^{-1}\right)$ and an IC of 0.36 litre $\left(5.5 \mathrm{ml} \cdot \mathrm{kg}^{-1}\right)$ and was known to be a high risk. However, it was felt that since the operation would enable him to sit up, it should be done. On the other hand, another patient with a VC of 1.04 litres ( 19 per cent of predicted $16.7 \mathrm{ml} \cdot \mathrm{kg}^{-\mathrm{I}}$ ) and an IC of 0.83 litre $\left(13.3 \mathrm{ml} \cdot \mathrm{kg}^{-1}\right)$ had no respiratory difficulties.

Therefore it would appear that a VC of at least $20 \mathrm{ml} \cdot \mathrm{kg}^{-1}$ and an IC of at least $15 \mathrm{ml} \cdot \mathrm{kg}^{-1}$ would be adequate for patients with muscular dystrophy undergoing spinal fusion. Of the six patients in whom the VC was determined (range 12-68 per cent of predicted), one had a value of 19 per cent and two had values of 32 per cent of predicted volumes. These patients did not require ventilatory assistance. Thus the minimum percentage of the predicted vital capacity would seem to be in the range of 30 per cent. These objective measurements have to be considered along with many other factors including the rapidity of progression of the muscular weakness, other respiratory and cardiovascular complications and problems such as obesity before an accurate assessment of risk can be made. In addition, patients should be in optimum condition before operation, with antibiotic therapy for purulent sputum, mobilization of secretions by chest physiotherapy, and should have sufficient motivation.

\section{REFERENCES}

1. Gibson, D.A., Koreska, I., Robertson, D., KAHN, A \& ALBISSER, A. The Management of Spinal Deformity in Duchenne's Muscular Dystrophy. Orthopedic Clinics of N. America. 9: $437-450$ (1978)

2. Pecak, F., Trontelu, J.V. \& Dimitrijevic, O.O. Scoliosis in Neuromuscular Disorders. International Orthopaedics 3: 323-328 (1980).

3. HutTENLOCHER, P.R. Neuromuscular Diseases Textbook of Pediatrics. Edited by Nelson, W.E., Vaughan, V.C., McKay, R.J., Behrman, R.E., Toronto, W.B. Saunders, 11th. Ed., pp 18061807 (1979)

4. EluIs, F.R. Inherited Muscle Disease, Br. J. Anaesth. 52: 153-164 (1980).

5. Boltshauser, E., Steinmann, B., Meyer, A. \& Jerusalem, R. Anaesthesia Induced Rhabdomyolysis in Duchenne Muscular Dystrophy. Br. J. Anaesth. 52: 559 (1980)

6. BERGOFSKY, E.H. Respiratory Failure in Disorders of the Thoracic Cage. Am. Rev. Respir. Dis. 119: 643-669 (1979)

7. Levine, D. B. Pulmonary Function in Scoliosis. Orthopedic Clinics of N. America 10:761-768 (1979).

8. Froese, A.B. Preoperative Evaluation of Pulmonary Function. Pediatric Clinics of $N$. America 26: 645-659 (1979).

9. Shneerson, J.M. \& Edgar, M.A. Cardiac and Respiratory Function Before and After Spinal Fusion in Adolescent Idiopathic Scoliosis. Thorax 34: 658-661 (1979).

10. Shapiro, B.A., Harrison, R.A. \& Trout, C.A. Clinical Application of Respiratory Care. Chicago: Year Book Medical Publishers, Inc., p. 466 (1979).

11. Malmberg, R., Dottori, O., Berglund, E., Simonsson, B.G. \& Bergh, N.P. Pre-operative Spirometry in Thoracic Surgery. Acta Anesthesiol. Scand. 9: 57-64 (1965)

12. Robin, G.C. Scoliosis in Duchenne Muscular Dystrophy. Israel. J. Med. Sci. 13: 203-206 (1977).

\section{RÉsumé}

Les auteurs ont revu les dossiers de 10 patients presentant une dystrophie musculaire (syndrôme de Duchenne dans neuf des cas et de Becker dans le dixième); ces patients avajent tous été opérés pour correction de scoliose par fusion sternale et fixation au moyen 
d'une tige de Harrington. L'âge moyen des patients était de 15 ans et l'angulation moyenne de leur scoliose était de 69 degrés.

Les épreuves de fonction respiratoires effectuées avant l'intervention ont mis en évidence des atteintes restrictives (capacité vitale moyenne de $1.3 \pm 0.6$ litres, soit en moyenne $35 \pm 20$ pour cent des valeurs prédites et capacité inspiratoire moyenne de $0.99 \pm 0.5$ litres.

On n'a pas relevé de complications anesthésiques au cours des interventions, ni de problèmes reliés à une cardiomyopathie obstructive ou d'hyperkaliémie, d'hyperthermie ou de rhabdomyolyse. La succinylcholine a été évitée dans tous les cas. Un des patients a présenté une arythmie post-opératoire. Un autre malade, le seul qui n'a pu être extubé en fin d'intervention, n'a pu être sevré de son respirateur et est décédé onze semaines après l'intervention, ayant été trachéostomisé et ayant présenté un tableau septique avec pneumonie bilatérale et infection urinaire.

L'évaluation du risque opératoire est surtout centrée sur l'évaluation de la fonction pulmonaire. Une capacité vitale d'au moins $20 \mathrm{ml} \cdot \mathrm{kg}^{-1}$, soit environ 30 per cent des valeurs normales prédites, associée à une capacité inspiratoire d'au moins $15 \mathrm{ml} \cdot \mathrm{kg}^{-1}$, semble adéquate pour une chirurgie de Harrington. Les autres facteurs de risque à considérer sont la rapidité de progression de l'atteinte musculaire, la présence d'autres problèmes respiratoires, cardiovasculaires ou autres, ainsi que l'obésité. 